\title{
The Impact Of The Supplemental Instruction Leader On Student Performance In Introductory Accounting
}

\author{
Jefferson P. Jones, Auburn University, USA
}

\begin{abstract}
This study explores the association between a supplemental instruction (SI) program and student performance in an introductory accounting course. SI is a proactive academic support program that is aimed at improving student learning in traditionally "high-risk" college courses by integrating learning and critical thinking strategies with technical course content. This paper examines and describes the classical SI model as it has been applied in both non-business and business disciplines. We then extend the work of Etter, Burmeister, and Elder (2000) and Jones and Fields (2001) which examine the effectiveness of the SI model in introductory accounting by providing empirical tests after controlling for differences in SI group leaders. The SI leader's duty is to provide structure to the collaborative learning environment and to integrate study skills and learning strategies with course content. However, empirical analysis incorporating controls for differences in SI leaders is lacking. Results, based on both nonparametric chi-square analysis and analysis of covariance (ANCOVA) indicate that SI is an effective program that increases academic performance as measured by total points earned in the course. Further, results suggest that the SI program remains effective across multiple SI leaders.
\end{abstract}

Keywords: Supplemental Instruction; Student Performance; Accounting

\section{INTRODUCTION}

ntroductory accounting often provides students with their first exposure to the use of accounting information in making business decisions and serves as a foundation for the development of the necessary skills for a successful professional career (e.g., AECC, 1992). However, the technical demands and mechanical approach employed in this course has often led to discouragement, failure and overall poor student perceptions of the accounting profession (Cohen and Hanno, 1993; Geiger and Ogilby, 2000; Albrecht and Sack, 2000). The purpose of this study is to investigate the role of Supplemental Instruction (SI) as a means of achieving the objective of enhancing the student's educational experience.

Originally developed at the University of Missouri-Kansas City to address rising attrition rates in the health sciences programs, SI is a proactive academic support program that is aimed at improving student learning in "highrisk" college courses. ${ }^{1}$ SI research has consistently shown that SI participants have outperformed their non-SI peers with regard to course grade (Blanc, DeBuhr, and Martin, 1983; Congos and Schoepes, 1993; Jones and Fields, 2001). In addition, SI is designed to improve students' critical thinking and study skills through demonstration of learning and thinking strategies specific to the course (Martin and Arendale, 1994). It is the integration of these skills with technical course content that is hypothesized to allow students to achieve the technical competence desired in a course, such as accounting, while still delivering the skill instruction necessary to serve as a foundation for life-long learning.

\footnotetext{
${ }^{1}$ High-risk, in this context, is defined as those courses in which $30 \%$ or more of the assigned grades are either failing ("D" or "F") or withdrawals. This definition is consistent with prior SI research.
} 
This study explores the association between the SI program and academic achievement in an accounting context. Initial analysis supports prior findings that SI is significantly associated with increased student performance in Principles of Accounting (Etter et al., 2000; Jones and Fields, 2001). The implementation of an effective SI program involves the use of SI group leaders to provide structure to the SI sessions and integrate study skills and learning strategies with course content. However, no current study exists that empirically examines the impact of multiple SI leaders on student performance. Given the important role of the SI leader, we extend the prior research by investigating the impact of multiple SI leaders on the effectiveness of the SI program. Results indicate that the SI program remains effective across multiple SI leaders.

\section{THE SI MODEL AND PREVIOUS RESEARCH}

\section{The SI Model}

SI is an academic assistance program with a goal of increasing academic performance and student retention while maintaining high academic standards. SI involves the use of voluntary small-group sessions that are facilitated by a fellow student (the SI leader) who has demonstrated prior competency in the course. It is in these small-group sessions that the SI leader models the study practices of a successful student and assists students in processing content and in identifying appropriate learning strategies. The SI model draws upon ideas from developmental psychology and attempts to use collaborative learning strategies that encourage a student to become actively involved in their own learning. Most collaborative learning models are relatively unstructured models in which students, by discussing ideas and concepts among themselves, are exposed to and draw upon others' expertise and learn from each other. SI adapts this collaborative model by using the SI leader as a facilitator whose job is to keep the group on task. Thus, SI may be thought of as a structured collaborative model that is designed to assist students in mastering course concepts while increasing their reading, reasoning, and study skills.

Three key features of the SI model deserve attention. ${ }^{2}$ First, SI targets traditionally difficult or "high-risk" courses having a high proportion of failing ("D" or "F") or withdrawal grades. By targeting the high-risk courses instead of the high-risk students, SI avoids the remedial stigma that is often associated with traditional academic assistance programs. Therefore, many students who would not participate in a remedial program may opt to participate in SI. Additionally, no pre-screening of students is necessary, resulting in SI sessions being comprised of students with varying abilities (Martin and Arendale, 1994). This variation in ability should result in a more productive collaborative learning experience during the SI sessions. An additional benefit of focusing on the course rather than the student is that a context is provided in which to learn skill instruction. In an SI setting, students are able to both master course content and develop life-long learning skills.

A second feature of the SI model is that it is a proactive program that recognizes that there may be a mismatch between the level of instruction and the level of student preparation. Rather than reacting to academic difficulties, the SI program provides regularly scheduled, out-of-class sessions that begin in the first week of the term. If a student's level of preparation does not meet the level demanded by the course, the student is able to receive assistance through SI sessions that should help align his expertise with that expected of the course. Additionally, as new material is covered, the SI sessions allow the student, through the collaborative learning experience, to clarify concepts, details, and study strategies that were not initially grasped or understood. Overall, the student is able to receive assistance early in the course prior to encountering academic difficulties.

A final feature of the SI model is that academic assistance consists of small-group sessions that are facilitated by an SI leader. The SI leader is a fellow student who has demonstrated past competence in the course and has been hired specifically to conduct the small-group sessions. The leader receives training in collaborative/group learning strategies and techniques and is required to attend all class sessions, take notes and read all assigned material. The leader then serves as a facilitator in multiple, out-of-class, small-group sessions per week. The leader does not lecture, introduce new material, ask content-related questions, nor give answers. Instead, the leader's role is to provide structure to the collaborative learning environment and integrate study skills and learning strategies with the course content. The focus of the SI session is how to learn and understand course content. It is

\footnotetext{
2 The discussion in this section is drawn from Martin and Arendale (1994). 
this combination of learning strategies in a specific context that provides the student with the foundation necessary for not only current but future success.

\section{Benefits of SI}

Proponents claim SI programs provide two major benefits: increased student retention and enhancement of the educational experience. At the university level, the inability to retain students remains a costly problem. The longer a student takes to complete his degree, the higher the costs to the student, the university and society. Obviously, the cost to the student is increased when a course has to be repeated, but the costs to the university and society often are not as noticeable. Universities incur significant infrastructure costs when students repeat courses in terms of increased class sizes and additional sessions being offered. Additionally, every time a student is lost to attrition, the university has lost income until that student is replaced, and research has shown that it costs more to recruit a student than it does to retain one (Congos and Schoeps, 1997). At the departmental level, solutions to declining enrollments in the accounting curriculum may lie in the assistance given to students in the introductory course. It stands to reason that if SI is able to make the technical barrier to entry to the accounting profession less severe without sacrificing academic standards, students' perceptions of the accounting discipline will change. This change in perception may lead to increased interest in accounting as a career path.

In addition to increasing retention, SI has been suggested to enhance the students' educational experience. The AECC's Position Statement \#1, "Objectives of Education for Accountants" clearly articulates the goal of accounting programs - to lay a base on which life-long learning can be built by "teaching students to learn on their own" (AECC, 1990). This is precisely the advantage of SI. By focusing on teaching learning strategies that foster critical thinking and learning skills, SI develops a students understanding of the underlying principles and concepts so that he will have the ability to apply these concepts and principles in different settings. Additionally, the group setting of SI sessions promotes a high degree of student interaction that develops students' interpersonal and communications skills. These proposed skills (although not the SI model specifically) have been advocated by the $\mathrm{AECC}$ as a means to improve accounting education.

\section{PREVIOUS RESEARCH}

Considerable research has explored the effectiveness of SI in non-business disciplines. Blanc, Debuhr, and Martin (1983) investigated the impact of SI on 746 students enrolled in seven "high-risk" Arts and Sciences classes and found that while the students who participated in SI (SI group) and those that did not participate (non-SI group) appear equivalent in terms of prior academic achievement, the SI group had a significantly higher semester GPA, higher course, and lower withdrawal rate than the non-SI group. Further, the reenrollment rate over the subsequent two semesters for the SI group was higher than the reenrollment rate for the non-SI group. Congos and Schoeps $(1993,1997)$ extend this research by applying more rigorous statistical procedures and introducing variables to control for students' motivation, industriousness and possible self-selection bias. Other studies reaching similar decisions in non-accounting-related disciplines include Burmeister et al. (1996) in mathematics, Loviscek and Cloutier (1997) in microeconomics, and Webster and Dee (1998) in engineering.

Etter et al. (2000) is the first study to examine SI in introductory accounting. While descriptive evidence is provided with regard to the effectiveness of SI in the introductory accounting course, no statistical analysis is provided. Jones and Fields (2001) provide empirical analysis of both the classical SI model (voluntary participation) and a mandatory participation SI model. Results suggest that SI is effective in both the voluntary and mandatory settings. In addition, a step pattern is observed in the increased performance for both the voluntary and mandatory attendance phases of the study, indicating that the level of SI attendance may play a role in the benefits obtained. This study extends Jones and Fields (2001) by providing evidence on the impact of multiple SI leaders on the effectiveness of the SI program. 


\section{RESEARCH OBJECTIVES AND METHODOLOGY}

\section{Research Objectives and Study Description}

Our major research objective is to empirically assess the impact of multiple SI leaders on the efficacy of the SI model within the accounting curriculum. While the SI program has been shown to be, on average, effective across many disciplines, it is possible that the effectiveness of SI varies across SI leaders. The SI leaders, while trained in collaborative learning techniques, may differ in their ability to implement these techniques. Because the SI leader plays such a crucial role in the day-to-day functioning of the SI program, it is vital to know if there is variance in the effectiveness of SI across SI leaders in order that remedial actions (e.g., additional training, amended selection methods) can be conducted to increase the benefits obtained from an SI program.

SI was implemented for the Principles of Accounting course at a large public university in the Southeastern United States. This introductory accounting course is a lecture-oriented course required of all business majors and is typically taught in relatively large class sizes. In addition, this course qualifies as "high-risk" under the typical SI definition as it has consistently exhibited a greater than $40 \%$ rate of failing ("D" or "F") and withdrawal grades.

The implementation of the SI program proceeded as follows. During the first two weeks of the academic term, the SI program was described to the students and they were informed of the opportunity to participate and assigned an SI session; however, no special incentives were offered and attendance at SI sessions was voluntary. Eleven SI sessions were offered, and each session was conducted by an SI leader who had previously demonstrated competence in the Principles of Accounting course as evidenced by a grade of A or B. Each of these potential leaders was interviewed in order to assess the effectiveness of their communication skills. Each of the SI leaders selected to participate in the program attended training sessions to learn how to properly conduct the SI session. During these sessions, the SI leaders were instructed to attempt to stimulate discussion but to never lecture or work homework problems. The SI leaders were also required to attend weekly organizational/training meetings during the academic term as part of their employment.

Student achievement was assessed through the student's final grade as determined by the total of their exam scores received on four objective examinations. This final grade is expressed in terms of total points on the four exams (TTLPTS), the letter grade received, and the grade point average (GPA) for the course. The letter grades of A, B, C, D, F, as well as the grade point average, were calculated using a 10 percentage point scale of TTLPTS. Neither TTLPTS nor GPA includes the effects of homework, projects, lecture attendance, SI participation, or any other method of obtaining points in the class. The level of SI attendance (SIATTEND), representing the total number of SI sessions attended by the student, was recorded by the SI leader. Because the level of SI attendance will be correlated with whether the student has withdrawn, TTLPTS and GPA are calculated after excluding the withdrawn students.

Previous research on educational production functions suggest that academic ability and prior academic performance are also intervening variables that result in differential student performance (Eskew and Faley, 1988; Doran et al., 1991; Wooten, 1998). Following prior research, we collected information on students' prior grade point averages (PGPA), and SAT scores (SAT) from college transcripts as a means of capturing differences in academic ability and effort. ${ }^{3}$

\section{Methodology}

Two types of analyses are performed to assess the effectiveness of the SI program. First, because one measure of SI success, final course grade, is a nominal (classification) variable, a nonparametric chi-square analysis will be performed to determine whether course grade differs significantly between SI and non-SI participants. SI

\footnotetext{
${ }^{3}$ While self-reported data on these variables could have been collected, previous research has shown that such self-reported data is often inaccaurate (Maxwell and Lopus, 1994, Wilson, et. al., 1994). For students who took the ACT rather than the SAT, ACT scores were converted to the equivalent SAT score using an ACT-to-SAT conversion table used by University administration. ACT/SAT scores reflect only the critical reading/verbal and mathematics sections of the test.
} 
participation will be a dichotomous classification based on whether the student chose to participate in SI or not. Following prior literature, students will be classified in the SI group if they attended 5 or more SI sessions (Congos and Schoeps, 1993, 1997). Results from this analysis should indicate whether there is an association between participation in the SI program and course grade. Second, analysis of covariance (ANCOVA) will be employed to assess the effectiveness of the SI program. In ANCOVA, the relationship between SI attendance and cumulative exam score (TTLPTS) is examined after blocking on the student's gender (GENDER), and the student's major (MAJOR). The blocking procedure groups students with the same gender and similar major so that performance differences that can be attributed to these factors can be eliminated, resulting in an increase in precision of the test. Additionally, a covariate (students' SAT/prior GPA) will be included in an attempt to capture students' ability and/or motivation prior to the introduction of SI. The inclusion of this pre-treatment covariate allows for increased precision in the examination of the mean cumulative exam scores of SI participants (or non-participants) after adjusting for students' prior academic ability and motivation. ${ }^{4}$

\section{EMPIRICAL RESULTS}

\section{Descriptive Statistics}

The sample consisted of 323 students enrolled in the Principles of Accounting course. Descriptive statistics are provided in Table 1. Several items are of note. First, the course appears to have met the standards for a highrisk course, with students earning approximately $70 \%$ of the total points available for the quarter with an average class GPA below 2.0. Second, the magnitude of the students' SAT and PGPA variables indicate that the students do possess the ability to perform well and have performed well in other classes in the past. This further confirms the selection of this course as one that is a viable SI candidate. Third, while the percentage of the class participating in SI was large (approximately 56\% of the class participated), attendance at SI sessions was low. To gauge the level of attendance, a subset of SI attendance is formed (SI_SUB) that includes only those students who attended at least one SI session. Of the 183 students who chose to attend at least one SI session, the average number of sessions attended was six out of a possible 17 sessions.

Table 1: Descriptive Statistics

\begin{tabular}{|l|c|c|c|c|c|}
\hline \multicolumn{1}{|c|}{ Variable } & Mean & Median & $\begin{array}{c}\text { Standard } \\
\text { Deviation }\end{array}$ & Minimum & Maximum \\
\hline TTLPTS & 283.78 & 288.13 & 53.55 & 34.00 & 389.37 \\
\hline GPA & 1.71 & 2.00 & 1.16 & 0 & 4.0 \\
\hline SIATTEND & 3.89 & 2.00 & 4.66 & 0 & 17 \\
\hline $\begin{array}{c}\text { SI_SUB } \\
\text { (N=183) }\end{array}$ & 6.86 & 6.00 & 4.24 & 1 & 17 \\
\hline SAT & 1080.93 & 1070 & 122.57 & 0.92 & 1470 \\
\hline PGPA & 2.50 & 2.44 & 0.58 & 0.92 & 4.0 \\
\hline
\end{tabular}

\section{Empirical Tests}

Our initial tests focused on whether any relationship exists between SI attendance and the letter grade received. We classify all students into one of four categories:

1. $\quad$ Attended SI and received a passing grade $(\mathrm{A}, \mathrm{B}$, or $\mathrm{C})$

2. $\quad$ Attended SI and received a failing grade (D, F, or W)

3. Did not attend SI and received a passing grade $(\mathrm{A}, \mathrm{B}$, or $\mathrm{C})$

4. Did not attend SI and received a failing grade $(\mathrm{D}, \mathrm{F}$, or $\mathrm{W})$

Consistent with prior research (Congos and Schoeps, 1993 and 1997; Jones and Fields, 2001), students are classified as member of the SI group if they attended five or more SI sessions, while the non-SI group consists of

\footnotetext{
${ }^{4}$ An important assumption in ANCOVA with multiple covariates is the homogeneity of slopes assumption. The assumption allows the comparison of treatment means at the mean values of the covariates (the adjusted means). Analysis, not reported here, indicates that this assumption is met.
}

2013 The Clute Institute http://www.cluteinstitute.com/ 
students attending fewer than five sessions. A four-cell contingency table is then constructed and tested using the chi-square test for independence of classification.

Table 2 shows the actual and expected count for each cell. The overall significant chi-square statistic clearly supports the notion that the letter grade received is not independent of SI attendance. Examining each cell, the SI attendees appeared to earn passing grades more often than would be expected and to earn failing grades less often than expected. Further, the non-SI attendees earned fewer passing grades than expected and more failing grades than expected.

Table 2: The Association Between SI Attendance And Letter Grade Received

\begin{tabular}{|l|c|c|c|}
\hline & $\begin{array}{c}\text { Pass } \\
\text { Actual } \\
\text { (Expected) }\end{array}$ & $\begin{array}{c}\text { Fail } \\
\text { Actual } \\
\text { (Expected) }\end{array}$ & $\begin{array}{c}\text { Row } \\
\text { Totals }\end{array}$ \\
\hline Non-SI & $\begin{array}{c}97 \\
(108.84)\end{array}$ & 92 & 189 \\
\hline SI & 89 & $40.16)$ & 134 \\
\hline Column Totals & $(77.16)$ & $(56.84)$ & 323 \\
\hline$\chi^{2}(1$ d.f. $)=7.3149$ & 137 & & \\
Significance Level $=0.0068$ & & & \\
\hline
\end{tabular}

In order to examine the combined effects of SI attendance and academic potential on the total points earned and course grade point average after controlling for multiple SI leaders, an ANCOVA was conducted. Results are presented in Table 3.

Supporting the earlier results and previous research, the SI group significantly outperformed the non-SI group in terms of total points earned and grade point average. Given the effectiveness of SI, of more concern to our study is the impact of the SI leader (LEADER). The SI leader is found to be insignificantly associated with performance in the class. Therefore, it does not appear that differences in the abilities of the multiple SI leaders led to differences in academic performance. This result suggests that SI can be effective in large settings with multiple SI leaders, given that the SI leaders are appropriately trained.

With regard to the other variables in the model, it appears that gender, major, SAT, and PGPA all play important roles in academic performance. As expected, students with greater ability and motivation (as captured by SAT scores and students' PGPA) outperformed their less academically talented and motivated counterparts. In fact, ability and motivation are the primary determinants of academic performance as noted by the size of the sum of squares. Gender also appears to play an important role in performance with females outperforming their male counterparts. While much academic research in non-accounting fields tend to support male performance as being superior to female performance (e.g., Heath, 1989), it appears that female performance in accounting is superior to male performance. Thus, the gender effect may be highly contextual. A student's major (MAJOR) also played an important role. As expected, results indicate that business majors outperformed non-business majors while accounting majors outperformed other business majors and non-business majors. 
Table 3: Results of Analysis of Covariance

\begin{tabular}{|c|c|c|c|c|c|}
\hline $\begin{array}{c}\text { Dependent } \\
\text { Variable }\end{array}$ & & $\begin{array}{c}\text { Explanatory } \\
\text { Variables }\end{array}$ & $\begin{array}{c}\text { Type III } \\
\text { Sum of Squares }\end{array}$ & $\begin{array}{l}\text { Degrees of } \\
\text { Freedom }\end{array}$ & $\begin{array}{c}\text { F-Statistic } \\
(p \text {-value })\end{array}$ \\
\hline \multirow{6}{*}{ TTLPTS } & \multirow{4}{*}{$\begin{array}{l}\stackrel{0}{0} \\
\stackrel{0}{0} \\
\text { II }\end{array}$} & SI & 6055.04 & 1 & $\begin{array}{c}3.17 \\
(0.0761)\end{array}$ \\
\hline & & GENDER & $12,858.35$ & 1 & $\begin{array}{c}6.73 \\
(0.0099)\end{array}$ \\
\hline & & MAJOR & $17,677.19$ & 2 & $\begin{array}{c}4.63 \\
(0.0105) \\
\end{array}$ \\
\hline & & LEADER & $17,913.62$ & 11 & $\begin{array}{c}0.85 \\
(0.5879) \\
\end{array}$ \\
\hline & \multirow{2}{*}{ 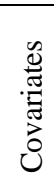 } & SAT & $38,751.54$ & 1 & $\begin{array}{c}20.28 \\
(<0.0001)\end{array}$ \\
\hline & & PGPA & $112,122.67$ & 1 & $\begin{array}{c}58.68 \\
(<0.0001)\end{array}$ \\
\hline \multirow{6}{*}{ GPA } & \multirow{4}{*}{ 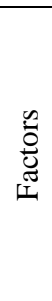 } & SI & 3.14 & 1 & $\begin{array}{c}3.51 \\
(0.0619)\end{array}$ \\
\hline & & GENDER & 8.32 & 1 & $\begin{array}{c}9.30 \\
(0.0025)\end{array}$ \\
\hline & & MAJOR & 12.44 & 2 & $\begin{array}{c}6.95 \\
(0.0011)\end{array}$ \\
\hline & & LEADER & 8.67 & 11 & $\begin{array}{c}0.88 \\
(0.5596)\end{array}$ \\
\hline & \multirow{2}{*}{ 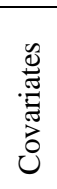 } & SAT & 20.61 & 1 & $\begin{array}{c}23.03 \\
(<0.0001)\end{array}$ \\
\hline & & PGPA & 44.86 & 1 & $\begin{array}{c}50.13 \\
(<0.0001)\end{array}$ \\
\hline
\end{tabular}

\section{CONCLUSIONS AND DISCUSSION}

This study examined whether participation in a SI program was associated with increased academic performance, as measured by the total points earned in the course and/or grade point average, and whether this performance was dependent on the specific SI leaders. Results indicate a significant association between SI participation and the total points received, irrespective of the SI leader. Specifically, the SI attendees appeared to earn passing grades more often than would be expected and to earn failing grades less often than expected. Further, these findings suggest that the implementation of the SI program using multiple SI leaders will not decrease the effectiveness of the SI model.

Overall, SI appears to be an effective program that increases academic performance. Additionally, the benefits of SI may extend beyond simply an increased grade in the course. SI's focus on developing learning strategies fosters the critical thinking skills that form a foundation for life-long learning. Because the student is better prepared in terms on grasping the underlying concepts and ideas, applications of these concepts to varied contexts should be more easily achieved. Additionally, the collaborative learning environment should also develop students' interpersonal and communications skills.

The above findings on the relation between SI and academic performance provide several opportunities for future research. First, while SI programs appear to increase academic performance, no evidence was provided that SI is preferable to other types of academic assistance (e.g., tutoring). Future studies may wish to compare student performance in an SI environment to these other forms of academic assistance. Second, one of the proposed benefits of SI is the development of study skills and learning strategies that serve as a basis for life-long learning. Future research may wish to assess whether SI actually improved students' higher order skills. Finally, the SI model has generally been examined in introductory courses. It may be beneficial to assess whether the documented relationship between SI and academic performance persists in higher level classes (e.g., intermediate accounting). 


\section{AUTHOR INFORMATION}

Jeff Jones is an Associate Professor of Accounting in the School of Accountancy at Auburn University. He has received numerous teaching awards and published articles in numerous professional journals, including Advances in Accounting, Review of Quantitative Finance and Accounting, and Issues in Accounting Education. Dr. Jones holds a C.P.A. certificate in the state of Alabama (inactive) and is a coauthor on Intermediate Accounting and Cornerstones of Financial Accounting. E-mail: jjones@business.auburn.edu

\section{REFERENCES}

1. Accounting Education Change Commission. (1996). Positions and Issues Statements of the Accounting Education Change Commission. Sarasota, FL: American Accounting Association.

2. Albrecht, W. S., and Sack, R. J. (2000). Accounting Education, Charting the Course Through a Perilous Future, Sarasota, Florida: American Accounting Association.

3. Blanc, R.A., Debuhr, L. E., and Martin, D. C. (1983). Breaking the attrition cycle: The Effects of Supplemental Instruction on Undergraduate Performance and Attrition. Journal of Higher Education (Jan/Feb): 80-90.

4. Burmeister, S., Kenney, P, and Nice, D. (1996). Analysis of Effectiveness of SI Sessions for College Algebra, Calculus, and Statistics. In Research in Collegiate Mathematics Education II (pp. 145-154). Providence, RI: American Mathematical Society.

5. Cohen, J., and Hanno, D. (1993). An Analysis of Underlying Constructs Affecting the Choice of Accounting as a Major. Issues in Accounting Education (Fall): 219-238.

6. Congos, D. H., and Schoeps, N. (1993). Does Supplemental Instruction Really Work and What Is It Anyway? Studies in Higher Education (June): 165-176.

7. _ and (1997). A Model For Evaluating Retention Programs. Journal of Developmental Education (Winter): 2-7.

8. Doran, M.B., Bouillon, M.L and Smith C.G. (1991). Determinants of Student Performance in Accounting Principles I and II. Issues in Accounting Education (Spring): 74-84.

9. Eskew, R. K., and Faley, R. H. (1988). Some Determinants of Student Performance in the First CollegeLevel Financial Accounting Course. The Accounting Review (January): 137-147.

10. Etter, E. R., Burmeister, S. L., and Elder, R. J. (2000). Improving Student Performance and Retention via Supplemental Instruction. Journal of Accounting Education (Autumn): 355-368.

11. Geiger, M.A., and Ogilby, S.M. (2000). The First Course in Accounting: Students' Perceptions and Their Effect on the Decision to Major in Accounting. Journal of Accounting Education 18 (Spring): 63-78.

12. Heath, J. A. (1989). “An Econometric Model of the Role of Gender in Economic Education” American Economic Review, Proceedings (May): 226-230.

13. Jones, J.P. and Fields, K.T. (2001). The Role of Supplemental Instruction in the First Accounting Course. Issues in Accounting Education (November): 531-547.

14. Loviscek, A.L., and Cloutier, N.R. (1997). Supplemental Instruction and the Enhancement of Student Performance in Economics Principles. The American Economist (Fall): 70-76.

15. Martin, D.C., and Arendale. D.R. (1994). Supplemental Instruction: Increasing Achievement and Retention. San Francisco: Jossey-Bass.

16. Maxwell, N.L., and Lopus, J.S. (1994). The Lake Wobegon Effect in Student Self-Reported Data. American Economic Review, Proceedings (May): 201-205.

17. Webster, T., and Dee, K. (1998). Supplemental Instruction Integrated Into An Introductory Engineering Course. Journal of Engineering Education (October): 377-383.

18. Wilson, T.E., Jr., Ward, D.R. and Ward, S.P. (1994). Use of Self-Reported College Aptitude Test Scores in Accounting Education Research. Psychological Reports (February): 327-328.

19. Wooten, T.C. (1998). Factors Influencing Student Learning in Introductory Accounting Classes: A Comparison of Traditional and Nontraditional Students. Issues in Accounting Education (May): 357-373. 